Long term evolution of adult onset Still's disease seen in an infectious diseases department

Sir: Adult onset Still's disease was first reported by Bywaters ${ }^{1}$ in 1971 , who stated that the long term articular prognosis was good. Several studies have shown, however, that severe joint lesions do occur and often leave patients with severe sequelae. ${ }^{2-5}$ Cabane et $a l^{5}$ found that the incidence of hip disease was $50 \%$ and that hip replacement was required in seven out of 18 cases. This letter reports the long term outcome of 10 patients with adult onset Still's disease who presented to an infectious diseases department and were followed up for more than three years.

All 10 patients were more than 16 years old (mean 36 years (range 20-56)) and fulfilled the American Rheumatism Association criteria for adult onset Still's disease ${ }^{6}$; in eight patients all four major criteria (fever, arthritis, rash, leucocytosis) were present and the diagnosis was definite. Diagnosis was only probable in two patients because of the absence of the characteristic rash. Arthritis most commonly affected the knees (seven patients), wrists (four), and ankles (two), and was monarticular (six) or pauciarticular (four) in distribution. The patients were followed up for a mean of 8.9 years (range $3-17$ ).

Long term outcome was assessed according to the disease activity scale defined by Cush $e t$ $a l^{2}$ and is reported in the table. Systemic disease activity was the dominant aspect of the illness in eight out of $\mathbf{1 0}$ patients in whom articular involvement was mild or absent. Five of these eight patients had a single episode of systemic disease followed by clinical and biological remission. Currently, they have discontinued treatment after a mean duration of 20 months and a mean follow up period of six years. Three of these eight patients had a polycyclic systemic disease pattern defined by multiple episodes of systemic disease without severe articular involvement. Chronic articular disease was identified in two other patients with polycyclic systemic disease superimposed on persistent peripheral arthritis. Joints in these two patients, including shoulders, wrists, and knees, were affected with asymmetric polyarticular disease. It should be patients were negative for rheumatoid factor. Radiographs showed moderate subchondral erosions without narrowing of the articular space. Chronic arthritis in these two patients was controlled by a methotrexate regimen. The first patient was treated with this drug for two years (15 mg weekly) and is now asymptomatic, 2.5 years after discontinuation of all treatment. The methotrexate regimen was recently started by the second patient and is controlling the arthritis. Corticosteroid noted that the hip joints were spared. The

treatment alone had been ineffective in both these patients. Articular destruction was moderate in both patients and arthrodesis or articular protheses were not required. Finally, the outcome for all 10 patients was favourable and they remained in functional class $I$ of the American Rheumatism Association functional status classification.

Our observations confirm the favourable prognosis of the systemic manifestations of adult onset Still's disease. Furthermore, they suggest that the prognosis of the articular manifestations may also be favourable. This is not consistent with several earlier studies. ${ }^{3-5}$ This discrepancy might be due to differences in the way in which the patients were recruited. Our study group comprised patients admitted to an infectious diseases department owing to prolonged fever of unknown origin without prominent articular signs. Previous studies used groups of patients admitted to departments of internal medicine or rheumatology. Cush $e t a l^{2}$ indeed showed that patients with mild articular manifestations at presentation tend to have a considerably better functional status after prolonged follow up than those with more severe articular manifestations. The shorter follow up periods in this study, as compared with previous studies, might explain the more favourable articular prognosis suggested by our results. Nevertheless, in the group described by Cabane et $a l^{5}$ joint destruction appeared between one and eight years after the diagnosis and hip destruction in less than four years. In contrast, no hip disease or marked articular destruction were found in our patients with a mean follow up of 8.9 years.

BERTRAND GODEAU
CATHERINE LEPORT
CHRISTIAN PERRONNE
DOMINIQUE SALMON-CERON
JEAN-LOUIS VILDE
Department of Infectious
and Tropical Diseases
Bichat/Claude Bernard Hospital
Paris
France

MARCEL FRANCIS KAHN
Department of Rheumatology
Bichat/Claude Bernard Hospital
Paris, France

Correspondence to: Dr B Godeau, 68 Bd Arago, 75013 Paris, France.

1 Bywaters E G L. Still's disease in the adult. $A$ nn Rheum Dis 1971; 30: 121-33.

2 Cush J J, Medsger T A, Christy W C, Herber D C, Cooperstein L A. Adult onset Still' disease: clinical course and outcome. Arthritis Rheum 1987; 30: 186-94.

3 Larson E B. Adult Still's disease: evolution of a clinical syndrome and diagnosis, treatment, and follow-up of 17 patients. Medicine (Baltimore) 1984; 63: 82-91.

4 Ohta A, Yamaguchi M, Kaneoka H, Nagayoshi

T, Hiida M. Adult Still's disease: review of 228

Treatment and outcome of 10 patients with adult onset Still's disease followed up for more than three years

\begin{tabular}{lllcl}
\hline Case No & $\begin{array}{l}\text { Duration of } \\
\text { follow up } \\
\text { (years) }\end{array}$ & Treatment & $\begin{array}{l}\text { Duration of } \\
\text { initial treatment } \\
\text { (months) }\end{array}$ & Outcome \\
\hline 1 & 8 & CS, MTX & 12 & Chronic articular \\
2 & 14 & CS, MTX & 6 & Chronic articular \\
3 & 6 & CS & 36 & Polycyclic systemic \\
4 & 17 & CS & 8 & Polycyclic systemic \\
5 & 15 & CS & 180 & Polycyclic systemic \\
6 & 3 & CS & 5 & Monocyclic systemic \\
7 & 7 & CS, ASA & 30 & Monocyclic systemic \\
8 & $5 \cdot 5$ & CS & 30 & Monocyclic systemic \\
9 & $5 \cdot 5$ & ASA & 6 & Monocyclic systemic \\
10 & 8 & C &
\end{tabular}

*ASA = acetylsalicylic acid; CS = corticosteroid; MTX = methotrexate. cases from the literature. 7 Rheumatol 1987; 14: $1139-46$.

5 Cabane J, Michon A, Ziza J M, et al. Comparison of long term evolution of adult onset and of long term evilu's disease, juvenile onset Still's disease, both followed up for more than 10 years. Ann Rheum Dis 1990 49: 283-5.

6 Reginato A J, Schumacher H R, Baker D G, O'Connor C R, Ferreiros J. Adult onset Still's disease: experience in 23 patients and literature review with emphasis on organ failure. Semin Arthritis Rheum 1987; 17: 39-57.

\section{Septic arthritis due to Nocardia caviae}

Sir: A 75 year old man from a nursing home with past medical history of osteoarthritis, mild diet controlled non-insulin dependent diabetes mellitus, and hypertension was admitted in October 1988 with loculated left pleural effusion and infiltrates in the left lower lung field. Despite extensive evaluation no definite cause could be found. The patient was treated intravenously with antibiotics and was discharged after his condition stabilised.

In January 1990, while he was in hospital after peripheral vascular surgery, he developed left knee joint pain. Physical examination at that time showed an elderly, moderately built man with blood pressure $130 / 70$, pulse rate $84 / \mathrm{min}$, temperature $37 \cdot 5^{\circ} \mathrm{C}$. Chest examination showed decreased breath sounds and dry rales at the left base. There was a grade II/VI systolic ejection murmur at the right upper sternal border with regular heart rhythm. Examination of the left knee showed heat, marked tenderness, decreased range of motion, and moderate synovial effusion. The aspirated joint fluid was purulent and had a rosy colour. The white blood cell count showed $415 \times 10^{9}$ cells $/ 1$, of which $93 \%$ were neutrophils. Empirical treatment was started with nafcillin intravenously $6 \mathrm{~g} /$ day. After three days culture of this fluid yielded Nocardia caviae. Drug treatment was switched to trimethoprim 160 mg-sulphamethoxazole $800 \mathrm{mg}$ every 12 hours orally with subsequent addition of amoxycillin-clavulanate $500 \mathrm{mg}$ every eight hours orally. Blood and sputum cultures were negative. The chest radiograph was stable and showed persistent minimal left pleural effusion with pleural reaction, which had not changed for 14 months. An $x$ ray examination of the left knee showed degenerative changes, soft tissue swelling with joint effusion, and no sign of osteomyelitis.

Left knee arthrocentesis was performed periodically to monitor the progression of the disease. The leucocyte count in the synovial fluid gradually decreased with change of colour to opaque yellow despite persistent growth of $N$ caviae. After six weeks of antibiotic treatment the synovial fluid white cell count was $4.9 \times 10^{9}$ cells $/ 1$ and it was sterile. The patient's symptoms and signs of septic arthritis gradually improved. Treatment with amoxycillin-clavulanate was continued for a total of 12 weeks. Trimethoprimsulphamethoxazole was discontinued after eight weeks because of a minimal rise in blood urea and creatinine. No further synovial fluid accumulation has been noted, and the patient has continued to have a functionally stable left knee.

Nocardia caviae is an uncommon cause of human disease, usually seen in immunocompromised hosts. Although septic arthritis caused by $N$ asteroides ${ }^{1-3}$ and $N$ brasiliensis ${ }^{4}$ has been described, nocardial arthritis due to $N$ caviae, to our knowledge, has not been previously reported.

The predisposing factors for nocardial infection in the patient described here were mild, diet controlled non-insulin dependent 
diabetes mellitus and hypertension, inactive lifestyle at a nursing home with chronic osteoarthritis and minimal persistent left pleural disease of over one year's duration and of uncertain cause. The patient had also been treated for herpes zoster infection about one year before the development of nocardial arthritis. Possibly, therefore, he might have had a subnormal immune defence mechanism against opportunistic infections. The patient's chest radiograph showed marked improvement in pleural disease after treatment of the arthritis with trimethoprim-sulphamethoxazole/amoxycillin-clavulanate. This suggests that the portal of entry was the respiratory tract, and the patient might have had chronic pleural disease with culture negative nocardial infection.

Successful treatment of nocardial septic arthritis seem to require prolonged antibiotic treatment for three to six months or longer. ${ }^{5}$ From among all the antibiotics tested in vivo and in vitro, the use of trimethoprimsulphamethoxazole in the treatment of human nocardiosis has been well established. ${ }^{56}$ There is some evidence to suggest that amoxycillin-clavulanate may be useful in the treatment of nocardial infections.?

In summary, septic arthritis due to Nocardia caviae occurred in an elderly patient with multiple underlying diseases and was successfully treated with trimethoprim-sulphamethoxazole/amoxycillin-clavulanate combination antibiotic regimen. To our knowledge, $N$ caviae arthritis has not been previously reported. Nocardial infection must be considered when undiagnosed, longstanding pleuropulmonary disease persists in an immunocompromised patient who later develops septic arthritis. Finally, although it requires the long term use of antibiotics, septic arthritis due to $N$ caviae can be treated successfully.

\section{N P TORRE B K KIM Sisters of Charity Hospital 2157 Main Street Buffalo, New York 14214}

1 DiVittorio G, Carpenter J T Jr, Bennett J C. Arthritis in systemic nocardiosis. South Med $\dot{\mathcal{F}}$ Arthritis in systemi

2 Wilkerson R D, Taylor D C, Opal S M, Curl W W. Nocardia asteroides sepsis of the knee. Clin W. Nocardia asteroides sepsi

3 Rao K V, O'Brien T J, Anderson R C. Septic arthritis due to Nocardia asteroides after successful kidney transplantation. Arthritis Rheum 1981; 24: 99-101

4 Cons F, Trevino A, Lavalle C. Septic arthritis due to Nocardia brasiliensis(letter). $\mathcal{F}$ Rheumatol 1985; 12: 1019-21.

5 Curry W A. Human nocardiosis, a clinical review with selected case reports. Arch Intern Med 1980; 140: 818-26.

6 Adams H G, Beeler B A, Wann L S, Chin C K, Brooks G F. Synergistic action of trimethoprim and sulphamethoxazole for Nocardia asteroides: efficacious therapy in five patients. $A \mathrm{~m} \mathcal{J}$ Med efficacious therapy in
Sci $1984 ; 287: 8-12$.

7 Kitzis M D, Gutmann L, Acar J F. In-vitro susceptibility of Nocardia asteroides to 21 Blactam antibiotics, in combination with three B-lactamase inhibitors, and its relationship to the B-lactamase content. $\mathcal{F}$ Antimicrob Chemother 1985; 15: 23-30.

\section{Sex ratios in HLA related autoimmune disease}

Sir: With respect to the interesting article by James $^{1}$ we would like to describe data which support the hypothesis that sex ratios are disturbed in the families of probands with HLA related autoimmune disease.

Primary Sjögren's syndrome is a heterogeneous disease with a strong female pre-

Female:male sex ratio among family members of patients with primary Sjögren's syndrome

\begin{tabular}{|c|c|c|c|c|}
\hline & Women & Men & $\begin{array}{l}\chi^{2} \text { or Fisher's } \\
\text { test }\end{array}$ & p Value \\
\hline $\begin{array}{l}\text { Index cases (n) } \\
\text { Total relatives }{ }^{*}(\mathbf{n}) \\
\text { Relatives in studyt (n) } \\
\text { Siblings in study (n) } \\
\text { Offspring of probands (n) }\end{array}$ & $\begin{array}{r}38 \\
150 \\
142 \\
49 \\
19\end{array}$ & $\begin{array}{r}2 \\
74 \\
65 \\
27 \\
22\end{array}$ & $\begin{array}{l}20 \cdot 3 \\
13 \cdot 3 \\
95 \cdot 4 \\
3 \cdot 25 \\
0 \cdot 11\end{array}$ & $\begin{array}{l}<0.001 \\
<0.001 \\
<0.001 \\
<0.1 \\
<0.1\end{array}$ \\
\hline
\end{tabular}

*Refers to the potential pool of relatives.

tRefers to the relatives actually seen.

ponderance. $^{2}$ A large family study of the disease has been completed in north east England and confirmed the association between HLA-DR3 and primary Sjögren's syndrome. ${ }^{3}$ The families were ascertained from 40 white probands who all satisfied Fox's criteria for definite primary Sjögren's syndrome. ${ }^{4}$ Two hundred and seven relatives from a potential pool of 224 were included. The table shows the female:male sex ratio among the family members.

There was a trend for a female excess in siblings, though this did not reach statistical significance. A significant female preponderance, however, was seen in index cases and for the relatives as a whole. The availability of all the family pedigrees shows this to be a true phenomenon and not merely attributable to those consenting to the study.

We have reported definite/probable primary Siögren's syndrome occurring exclusively in the female relatives with a strong association with HLA-DR3 $(5 / 8(63 \%)) .^{3}$ In addition, a cohort of young relatives (under 45 years) who expressed some features consistent with primary Sjögren's syndrome were also identified. Twenty eight of these $\mathbf{4 5}$ subjects were female (female:male ratio $1 \cdot 65: 1, \chi^{2}=1 \cdot 365$, NS). For these women there was a strong association with HLA-DR3 (18/28 (64\%)) compared with the association for the men $\left(5 / 17(29 \%), \chi^{2}=3.85, \mathrm{p}<0.05\right)$. We suggested that these women may be at risk of developing definite primary Sjögren's syndrome in the future, and a prospective study will help to support or refute this hypothesis.

This suggests that the inheritance of HLADR3 may influence the sex ratio of the offspring as well as the susceptibility to primary Sjögren's syndrome.

\section{HELEN FOSTER CLIVE KELLY IAN GRIFFITHS \\ Department of Rhermatology Nezucastle upon Tyme NE1 4 LP}

1 James W H. Sex ratios and hormones in HLA related rheumatic diseases. Ann Rheum Dis

2 Strand $\mathrm{V}$, Talal $\mathrm{N}$. Advances in the diagnosis and concept of Sjögren's syndrome (autoimmune exocrinopathy). Bull Rheum Dis 1979; 30: 1046-76.

3 Foster H, Walker D, Charles P, Kelly C, Cavanagh G, Griffiths I. Association of DR3 with susceptibility to and severity of primary Sjögren's syndrome in a family study. $B r \exists R$ heumatol. In press.

4 Fox R I, Robinson C, Curd J, Cozin F, Howell F V. Sjögren's syndrome: proposed criteria for rheumatoid arthritis. Arthritis Rheum 1986; 29: rheumatoid

Nanocolloid scintigraphy for rheumatic diseases of the hands

Sir: The importance of early diagnosis of inflammatory rheumatic diseases has been emphasised recently. Nevertheless, the medical history and the physical examination of patients are difficult to assess, and laboratory and radiological modifications are often delayed. For several years scintigraphy has been proposed as a helpful device for diagnosis of initial or atypical bone and joint diseases. Most studies were performed with technetium-99m $\left({ }^{99 m} \mathrm{Tc}\right)$ bisphosphonates, but other isotopes are now available.' Among these, ${ }^{99 m}$ Tc labelled nanocolloid, which spreads to the extravascular space at sites of inflammation with increased vascular permeability ${ }^{2}$ is under study. As its clinical usefulness is still a matter for debate we compared joint pain, joint swelling, radiographs, and a palmar view scintigraphy (45 minutes after intravenous injection of 925 $\mathrm{MBq}$ of ${ }^{99 \mathrm{~m}} \mathrm{Tc}$ nanocolloid; 200000 counts or 15 minutes) of the hands of 27 subjects (seven controls, five patients with nodular osteoarthrosis, and 15 with classical or definite rheumatoid arthritis (RA)) who were examined in our department. The wrist, the metacarpal joints, the interphalangeal joint of the thumb, and the second to fifth proximal interphalangeal joints of each hand were included in the study, giving a total of 594 joints.

Joint pain and swelling, radiographic abnormalities, and nanocolloid scintigraphy were estimated on a four point scale: 0 representing a normal and 3 a very painful or swollen joint, a severe radiological change, or a marked increase of the isotopic uptake. The clinical assessment was made just after radiography and scintigraphy by an observer who was unaware of the results of the previous investigations. Six patients with $\mathrm{RA}$ also underwent ${ }^{99 m} \mathrm{Tc}$ diphosphonopropanedicarboxylic acid scintigraphy on adjoining days.

Joint isotopic uptake was usually easily discernible, but interpretation was difficult in several subjects owing to diffuse longitudinal uptake (fig 1) attributed to tenosynovial accumulation in three of seven controls, three of five patients with nodular osteoarthrosis (without tenosynovitis), and four of 15 patients

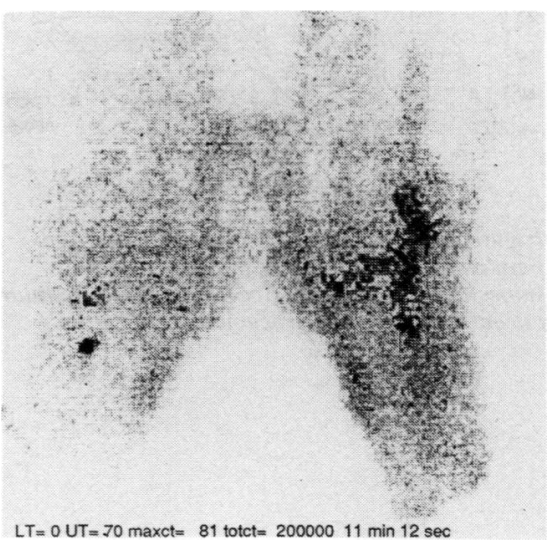

Figure 1 Technetium- $99 \mathrm{~m}$ labelled nanocolloid scintigram. Accumulation in the joints and along the tenosynovial sheath of the fourth left finger. 